Research Article

\section{Extraction of DNA from face mask recovered from a kidnapping scene}

\author{
Bassey Nsor* and Inuwa HM \\ Department of Biochemistry, Ahmadu Bello University, Zaria, Nigeria
}

\begin{abstract}
Deoxyribonucleic acid (DNA) extraction has considerably evolved since it was initially performed back in 1869. It is the first step required for many of the available downstream applications used in the field of molecular biology and forensic science. Blood samples is one of the main body fluid used to obtain DNA. This experiment used other body fluids such as saliva, sweat tears and mucus. There are many different protocols available to perform nucleic acid extraction on such samples. These methods vary from very basic manual protocols to more sophisticated methods included in automated DNA extraction protocols. This experiment used extraction kit (Zymo research). The DNA result from isolated saliva samples on the facemask range from 133.7, 213.6, 599.1 and $209.1 \mathrm{mg} / \mathrm{ml}$. theoretically; such DNA is of much quantity and quality and can be used for forensic investigation when recovered from a crime scene. The DNA from isolated tears samples on the face mask ranges from $707.7,202.5,99.2$, and $62.6 \mathrm{mg} / \mathrm{ml}$. Theoretically, such DNA is of much quantity and quality and can be used for forensic investigation when recovered from a crime scene. The DNA from isolated tears samples on the face mask ranges from 615.3, 66.2, 78.5, and $68.2 \mathrm{mg} / \mathrm{ml}$. theoretically, such DNA is of much quantity and quality and can be used for forensic investigation when recovered from a crime scene. Extracted DNA from saliva and sweat produced visible bands on agarose gel, mucous stain produce obscure band on agarose gel and the tears stain produce invisible bands. DNA from sweat satin, saliva stain, mucus stain and tears stain in face mask can be used as alternative for forensic investigation.
\end{abstract}

\section{More Information}

*Address for Correspondence: Bassey Nsor, Department of Biochemistry, Ahmadu Bello University, Zaria, Nigeria, Email: siregaius@gmail.com

Submitted: December 08, 2021

Approved: January 03, 2022

Published: January 07, 2022

How to cite this article: Nsor B, Inuwa HM. Extraction of DNA from face mask recovered from a kidnapping scene. J Forensic Sci Res. 2022; 6: 001-005.

DOI: 10.29328/journal.jfsr.1001029

Copyright License: () 2022 Nsor B, et al. This is an open access article distributed under the Creative Commons Attribution License, which permits unrestricted use, distribution, and reproduction in any medium, provided the original work is properly cited.

Keywords: DNA; Extraction; Face mask; Fluid; Kidnapping

D) Check for updates

OPEN ACCESS

\section{Introduction}

As technology advances on daily basis, new ideologies arise in using substantial evidence collected from crime scenes, these substance ranges from biological materials such as blood, hair strand, saliva, mucus, tears and other biological materials [1]. DNA which is present in every biological material can often be available on surfaces handled at a crime scene. Due to the limited amount of DNA in these samples, forensic professionalism and it extraction efficiency is very important if the samples are to be used as evidence in an investigation. Fabric (face mask) is chosen as a source for it high use in everyday crime scenes [1].

DNA analysis has become the golden standard in many crime laboratories around the world.

Deoxyribonucleic acid, commonly known as DNA, has become the "golden standard" for the identification of perpetrators at crime scenes [2]. This molecule contains the instructions necessary to create every type of cell in a person's body. Approximately $0.1 \%$ of DNA varies among people. This $0.1 \%$ is the main focus of forensic DNA investigations. Due to DNA's abundance in the body; multiple fluids can be used as a source for DNA. Good sources of DNA include blood, saliva, and semen, often visible to the naked eye [3].

Applying science to the legal area is fundamentally one of the noble ideologies that will greatly assist in determining what took place, where it happened when it happened and who was involved in the scene [4]. It is not involved in, and will not determine why something happened. But rather focuses on when it happens what happens and who was directly involved in the act [5]. Forensic investigation plays a major role on evidence in unveiling physical evidence so that crime or civil conflict can be resolved. It is the duty of the forensic scientist to collaborate with court of law in translating the legal issues into an appropriate [4]. The scientific question, and to advise the judiciary on the capabilities and limitations of current techniques.

Physical evidence (samples) collected from a crime scene are of a different kind, majorly samples that contain biological material (DNA) or samples that can have a stain of biological material (face mask, etc.) and the biological material can be extracted from it.

In forensic science, natural scientific techniques can be 
applied to determine the state of a piece of physical evidence at the time of collection. Using the scientific method, inferences are made about how the evidence came to be in that state. These inferences then limit the events that may or may not have taken place in connection with said evidence. The law interprets elements of a crime; science contributes evidence helping to determine if an element is present or absent. [3]. The inferential part of the forensic result must be emphasized. The scientific result presented in court does not conclude if the suspect is guilty or innocent. Rather, forensic science only unfolds information on what may have transpired and link the act to who may have been involved. It does not assert whether the action was legal or illegal.

In recent years, crime of different forms has been the major threat to life and property of Nigerians in Nigeria. Though some certain items such as metals and woolen materials are recovered from the crime scene and in some cases blood stains and saliva are found around the scene, yet the criminals are still not known. A study has shown that DNA being the genetic material of an organism is present in each material the organism comes in contact with. The material may be woolen linen or metal [2].

The unique nature of DNA variation from one individual to another individual makes it easy and possible to differentiate between every individual by DNA typing or fingerprint. Therefore when samples with DNA are collected from a crime scene, it becomes possible to trace the individual in whom sample was DNA was found in the scene. The extraction of DNA from a face mask can be a substantial evidence to prove whether a person is guilty of an accused crime or not. When such materials are collected from a crime scene and DNA extracted from them, the DNA will be compared with that of the suspect. If the crime scene DNA matches with that of the suspect, it therefore, proves the fact that the suspect used the face mask and can be used to link the suspect to the crime. But if the DNA did not match with that of the suspect, the suspect has no link to the crime except if there are other evidence to link the suspect to the crime [5]. In recent years, investigation depend on blood and hair strands from crime scenes for DNA fingerprinting, therefore other body fluids may not be necessary as a source of DNA for forensic investigation.

This work is limited to DNA extraction, quantification, and agarose gel electrophoresis. PCR, UV-vis spectrum absorption, gene sequencing and other molecular biology techniques are outside the scope of the research and therefore not captured.

\section{Materials and methods}

The materials used for the study include: Centrifuge (Frontier OHAUS), Electronic weighing machine (Adventurer OHAUS), Microwave and tips, samples, Face mask, Vortex mixer (BOHEMIA), Heat block (Grant BOEKEL), Gel thank and Nanodrop (Thermo scientific). The reagents used include; DNA KIT (ZYMO extraction kits), Agarose gel, Distilled water, Ethidium bromide.

\section{Sample collection}

Four people were invited to participate in the research, the eligibility criteria include healthy males and females adult age 18 years and above. The purpose of the study was explain to them and how they are expected to participate. Each participant was given face mask to wear for about one (1) to two (2) hours.

Participant A: undergo some form of rigorous exercise during the period in which the face mask was worn such that sweat from the face soaked the face mask, the face mask was carefully collected and soaked in a buffer inside a sample bottle to wash out the biological material (sweat) and the bottle was labeled for identification. Other samples being saliva, mucous, and tears were also collected from the participant for comparison and were also labeled for identification.

Participant B: was instructed to talk a lot during the time of putting on the face mask such that saliva expectorates on the face mask, the face mask was carefully collected and the part covering the mouth was carefully cut out into a buffer in a sample bottle to wash out the biological material (saliva) and the bottle was labeled for identification. Other samples being sweat, mucous, and tears were also collected from the participant for comparison and were also labeled for identification.

Participant C: was asked to cough in most of the time during which the mask is worn in other to expectorate mucus on the face mask, the face mask was carefully collected and the part covering the mouth was carefully cut out into a buffer in a sample bottle to wash out the biological material (mucus) and the bottle was labeled for identification. Other samples being sweat, saliva, and tears were also collected for comparison from the participant and were also labeled for identification.

Participant D: was asked to sniff methylated rob, this condition caused shading of tears from the eyes on the mask, the face mask was carefully collected and the part covering the eye was carefully cut out into a buffer in a sample bottle to wash out the biological material (tears) and the bottle was labeled for identification. Other samples being sweat, mucous, and saliva were also collected from the participant for comparison and were also labeled for identification.

\section{DNA extraction}

The samples transferred into sample bottles for safety reasons and labeled appropriately for easy identification. The label was given using numeric figures from 1 to 16 according to the numbers of samples collected. DNA was extracted from the samples following ZYMO extraction kits procedure. After the extraction, the DNA was quantified using NANODROP, a machine used in measuring the quality, purity and quantity of extracted DNA. The sample labeled one (1) to four (4) represent DNA from saliva, Sample labeled five (5) to eight (8) represent DNA from sweat, Sample labeled nine (9) to twelve 
(12) represent DNA from tears, Sample labeled thirteen (13) to sixteen (16) represent DNA from mucus.

\section{Agarose gel preparation}

$1 \%$ agarose gel was weighed using an electronic weighing balance (OHAUS) and was dissolved into $100 \mathrm{ml}$ of TAE buffer. The gel was melted in a microwave for 2 mins to form a homogeneous solution and was allowed to cool to about $60^{\circ}$ then $2 \mu \ell$ ethidium bromide (gel stain) was added. The gel was cast to a gel tank (Scie-PLAS) with a 16 well comb and allowed to solidify. The comb was removed gently to avoid distortion of the wells. The solidified gel was placed in a gel tank (Scie-PLAS) and the tank was filled with 1x TAE buffer till it submerge the gel.

\section{Agarose gel electrophoresis}

$2 \mu \ell$ of gel loading dye ( $6 \mathrm{x}$ blue) was pipetted on aluminum fuel and $10 \mu \ell$ of the individual DNA sample was mixed with the $2 \mu \ell$ of the gel loading dye ( $6 \mathrm{x}$ blue) and these were loaded into the gel wells of the tank.

The gel tank was connected to a light source. The samples were allowed to separate in the gel for 30 minutes. DNA is negatively charged, thus the DNA in the sample separated and moved toward the positive electrode.

\section{Results}

\section{Saliva samples}

Table 1 below shows the DNA result from the isolation of saliva stain from the samples' face mask ranging from 133.7, 213.6, 599.1 and $209.1 \mathrm{mg} / \mathrm{ml}$. theoretically; such DNA is of fair quantity and quality (best when amplified using PCR) and can be used for forensic investigation when recovered from a crime scene.

\section{Sweat samples}

Table 2 below shows the DNA result from the isolation of sweat stain from the samples' face mask ranging from 133.2, $310.2,253.3$ and $85.2 \mathrm{mg} / \mathrm{ml}$. theoretically; such DNA is of fair quantity and quality (best when amplified using PCR) and can be used for forensic investigation when recovered from a crime scene.

\begin{tabular}{|c|c|c|c|}
\hline \multicolumn{3}{|c|}{ Table 1: Isolation from Saliva Stain. } \\
\hline Samples No. & Level $(\boldsymbol{\mu g} / \mathbf{m l})$ & Quality $\left(\mathbf{A}_{\mathbf{2 6 0}} / \mathbf{A}_{\mathbf{2 8 0}}\right)$ & $\mathbf{A}_{260} / \mathbf{A}_{280}$ \\
\hline 1 & 133.7 & 1.49 & 0.59 \\
\hline 2 & 213.6 & 1.49 & 0.60 \\
\hline 2 & 599.1 & 1.48 & 0.62 \\
\hline 4 & 209.1 & 1.49 & 0.61 \\
\hline
\end{tabular}

Table 2: DNA Isolation from Sweat.

\begin{tabular}{|c|c|c|c|}
\hline Samples No. & Level $(\boldsymbol{\mu g} / \mathbf{m l})$ & Quality $\left(\mathbf{A}_{\mathbf{2 6 0}} / \mathbf{A}_{\mathbf{2 8 0}}\right)$ & $\mathbf{A}_{260} / \mathbf{A}_{\mathbf{2 8 0}}$ \\
\hline 1 & 133.2 & 1.47 & 0.65 \\
\hline 2 & 310.2 & 1.58 & 0.85 \\
\hline 3 & 253.3 & 1.46 & 0.61 \\
\hline 4 & 85.2 & 1.53 & 0.63 \\
\hline
\end{tabular}

\section{Tears samples}

The Table 3 below shows the DNA result from isolation of tears stain from the samples' face mask ranging from 707.7, 202.5, 99.2 and $62.6 \mathrm{mg} / \mathrm{ml}$. theoretically; such DNA is of fair quantity and quality (best when amplified using PCR) and can be used for forensic investigation when recovered from a crime scene.

\section{Mucus samples}

Table 4 below shows the DNA result from the isolation of mucus stain from the samples' face mask ranging from 615.3, $66.2,78.5$ and $68.2 \mathrm{mg} / \mathrm{ml}$. theoretically; such DNA is of fair quantity and quality (best when amplified using PCR) and can be used for forensic investigation when recovered from a crime scene.

Figure 1 shows the agarose gel electropherogram of DNA isolated from saliva, sweat, mucus and tears. Due to partial dissolution, only a few extracted DNA which are saliva and sweat DNA were able to produce visible bands. The extracted DNA with low quality mucous and tears showed invisible bands.

\begin{tabular}{|c|c|c|c|}
\hline \multicolumn{4}{|c|}{ Table 3: DNA Isolation from Tears. } \\
\hline Samples No. & Level $(\boldsymbol{\mu g} / \mathbf{m l})$ & Quality $\left(\mathbf{A}_{\mathbf{2 6 0}} / \mathbf{A}_{\mathbf{2 8 0}}\right)$ & $\mathbf{A}_{260} / \mathbf{A}_{\mathbf{2 0 0}}$ \\
\hline 1 & 707.7 & 1.39 & 0.70 \\
\hline 2 & 202.5 & 1.75 & 1.16 \\
\hline 3 & 99.2 & 1.40 & 0.60 \\
\hline 4 & 62.6 & 1.62 & 0.78 \\
\hline
\end{tabular}

Table 4: DNA Isolation from Mucus.

\begin{tabular}{|c|c|c|c|}
\hline Table 4: DNA Isolation from Mucus. \\
\hline Samples No. & Level $(\boldsymbol{\mu g} / \mathbf{m l})$ & Quality $\left(\mathbf{A}_{\mathbf{2 6 0}} / \mathbf{A}_{\mathbf{2 8 0}}\right)$ & $\mathbf{A}_{\mathbf{2 6 0}} / \mathbf{A}_{\mathbf{2 8 0}}$ \\
\hline 1 & 615.3 & 1.80 & 1.63 \\
\hline 2 & 66.2 & 1.85 & 1.70 \\
\hline 3 & 78.5 & 1.78 & 1.80 \\
\hline 4 & 68.2 & 1.85 & 1.71 \\
\hline
\end{tabular}

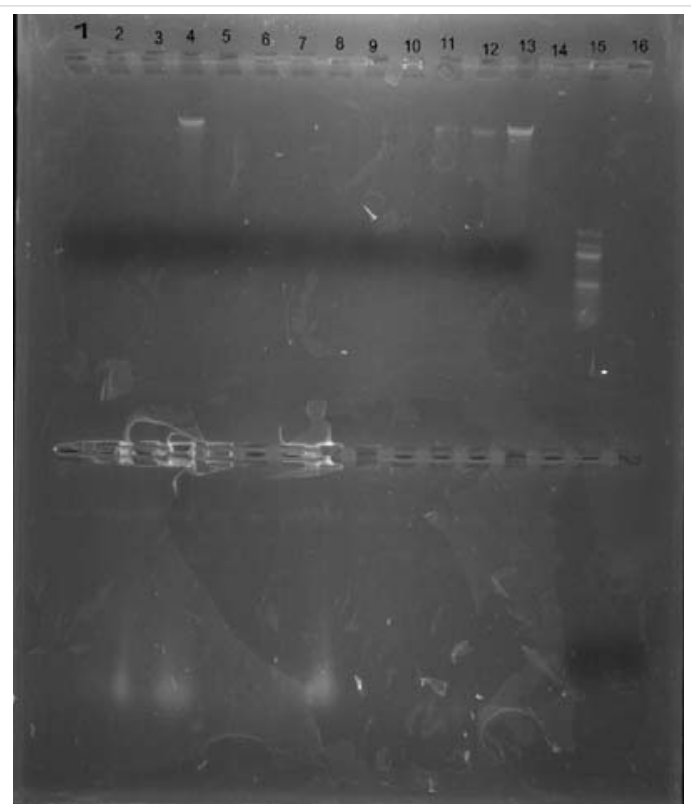

Figure 1: Agarose gel electropherogram result. 
From the agarose gel electropherogram result (Figure 1), the wells on the gel are numbered from 1 to 16 . In the experiment, four different samples being saliva, sweat, tears and mucus were used. From well one (1) to four (4) represent DNA from saliva, well five (5) to eight (8) represent DNA from sweat, well nine (9) to twelve (12) represent DNA from tears and well (13) to 16 represent DNA from mucus.

Figure 2 shows the agarose gel electropherogram of DNA isolated from saliva, sweat, mucus and tears, the gel was $1 \mathrm{~g}$ and dissolved completely on Microwave forming a homogeneous mixture and was most suitable for the research, therefore the DNAs move easily.

From the agarose gel electropherogram result (Figure 2), the wells on the gel are numbered from 1 to 16. In the experiment, four different samples being saliva, sweat, tears and mucus were used. From well one (1) to four (4) represent DNA from saliva, well five (5) to eight (8) represent DNA from sweat, well nine (9) to twelve (12) represent DNA from tears and well (13) to 16 represent DNA from mucus.

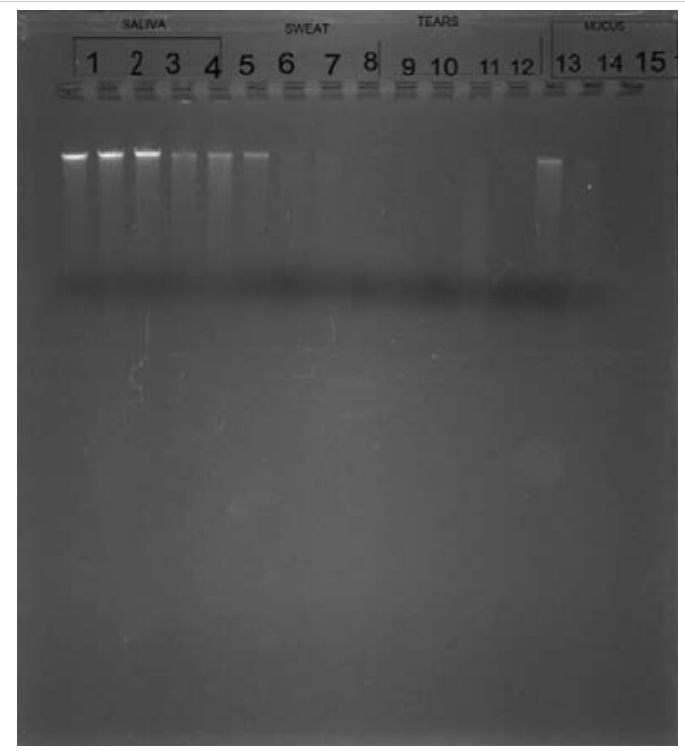

Figure 2: Agarose gel electropherogram result.

\section{Discussion}

\section{Comparative purity}

The DNA purity is evaluated by measuring absorbance from $230 \mathrm{~nm}$ to $320 \mathrm{~nm}$ to detect other possible contaminants. The most common purity calculation is the ratio of the absorbance at $260 \mathrm{~nm}$ divided by the reading at $280 \mathrm{~nm}$. Good-quality DNA will have an A 260 /A 280 ratio of 1.7-2.0. A reading of 1.6 does not render the DNA unsuitable for any application, but lower ratios indicate more contaminants are present. DNA purity (A $260 /$ A 280) $=($ A 260 reading - A 320 reading $) \div($ A 280 reading - A 320 reading)

From the results gotten from the saliva samples, the quality of the DNA ranges from 1.49 to 1.48 . This possibly is due to a high amount of bacterial contaminants and other possible contaminants present in the saliva.

In the sweat samples, the extracted DNA purity ranges between 1.46, 1.47, 1.53 and 1.58. Thus, indicating the presence of impurity or contaminants in the extracted DNA from sweat.

The result from the tears sample ranges between 1.37, $1.40,1.62$ and 1.72 . The result indicates good purity in two samples (1.62 and 1.72) with the other two samples having high level of impurity $(1.37,1.40)$. This possibly may be due to the presence of bacterial contaminants in the samples.

From the result gotten from the mucus samples, the quality of the DNA ranges between 1.78, 1.80 and 1.85 which shows a high level of purity.

Unlike blood samples, studies on sweat stain, saliva stain, mucus stain and tears stain have not been commonly performed. Many facts have not been disclosed, particularly those for forensic identification.

The amount of sweat stain, saliva stain, mucous stain and tears stain attached in the face mask, was limited and dry, which directly affected the level of DNA produced. Lower DNA level from sweat stain, saliva stain, mucous stain and tears stain in face mask affected the result of agarose gel electrophoresis visualization, where the DNA bands of the mucous and tears stain looked obscure. It can be therefore concluded that in certain trace evidence, sweat stain, saliva stain, mucous stain and tears stain can be noticed as they may be very valuable as an alternative for identification.

From the result above, 11 samples produced bands of different forms, the saliva and sweat samples produced bold bands while the mucous sample produced faint bands. However, 4 samples, which were tears samples from all the participants could not produce any band as a result of low quality DNA in them.

\section{Conclusion}

DNA from sweat stain, saliva stain, mucous stain and tears stain can be used as an alternative for forensic identification. Generally, DNA isolation from sweat stain, saliva stain, mucous stain and tears stain in face mask may have lower DNA level or quantity due to the minute amount of the body fluid present in the face mask

\section{Recommendation}

Extracted DNA from mucous stain produces an obscure band on agarose gel and the tears stain produces invisible bands, hence, the use of PCR techniques can be applied to amplify the bands for better analysis in conditions where those are the only samples collected from the crime scene. 
Nevertheless, when other stains like saliva and sweat stain are collected in minute quantity, PCR techniques can also be used to amplify the small amount of DNA, which, would add more value to the research.

\section{References}

1. Upadhyay R. Legal Status of Human Genetic Material- A Study Relating to Human DNA its Ethical Problems and Law. Kota: Department of Law University of Kota. 2018.

2. Martina N. Mitochondrial DNA in Sensitive Forensic Analysis. UPPSALA
Digital Comprehensive Summaries of Uppsala Dissertations from the Faculty of Medicine 220. 2007.

3. Akshay $\mathrm{V}$. The assessment of forensic molecular markers for skin colour in South Africans. Division of Forensic Medicine and Toxicology, Faculty of Health Sciences, University of Cape Town. 2019.

4. Allwood J. Using DNA to predict externally visible characteristics in humans for forensic use in New Zealand. PhD dissertation. The University of Auckland. 2013.

5. Ali-Khan SE, Tomasz K, Rabia T, Daar AS. The use of race, ethnicity and ancestry in human genetic research. Hugo J. 2011; 5: 47-63. PubMed: https://pubmed.ncbi.nlm.nih.gov/22276086/ 